Stanisław J. Skrzypek

Marcin Goły

Irena Dul

Tomasz Babul

Tomasz Korzeń

Mieczysław Choroszyński

\title{
Analiza fazowa złączy superstopów niklu ze stalą austenityczną lutowanych próżniowo
}

\section{Phase analysis of brazing in the high vacuum brazing of nickel-based superalloys and austenitic steel}

\section{Streszczenie}

Wysokotemperaturowe lutowanie próżniowe jest szeroko stosowane do metali i stopów pracujących w warunkach żaroodporności i żarowytrzymałości, które często zawierają powierzchniowe tlenki trudno ulegające dysocjacji. Dotyczy to superstopów zawierających $\mathrm{Ni}$ i Al, tworzące trwałe warstewki tlenkowe. Próżnia lub kontrolowana atmosfera służą do przeciwdziałania tworzeniu się tlenków i sprzyjają ich termicznej dysocjacji. Przed procesem lutowania wszystkie części muszą podlegać wstępnej obróbce oczyszczania powierzchni z powłok, smaru, oleju i z drobinek jakichkolwiek obcych substancji.

Zastosowano i omówiono próżniowe lutowanie super stopu Inconel 625 (X10NiNbCoAl58-4) z elementami ze stali austenitycznej (X10CrNiMn20-10-2) przy ciśnieniu ok. $1,3 \cdot 10^{-2} \mathrm{~Pa}$. Materiał lutowniczy (NiCrSiBFe) w formie folii o grubości $0,1 \mathrm{~mm}$ miał strukturę amorficzną. Po procesie lutowania struktura lutowia uległa przebudowie na fazy krystaliczne.

\section{Abstract}

The high temperature vacuum brazing is widely used in joining metals and alloys applied in high temperature loading machine parts. It is important particularly for alloys with surface layers of oxide, resistant to dissociation. Among them such materials as super alloys containing $\mathrm{Ni}$ and $\mathrm{Al}$ which easy crate stable layer oxides. Metal parts before brazing should have removed oxides, solid and mineral particles such as oil and grease.

In this paper some examples of brazing of Inconel 625 samples and austenitic stainless steel in aspect of metallography and phase composition are introduced. Brazing material in a form of foil $0.1 \mathrm{~mm}$ thick composed with $\mathrm{NiCrSiBFe}$ was in amorphous state. The joining plates $1 \mathrm{~mm}$ thick made of join alloys were annealed, mechanically prepared and cleaned. The brazing process was in vacuum at the pressure of $11,3 \cdot 10^{-2} \mathrm{~Pa}$. After solidification and cooling with furnace the brazing material appeared in specific metallographic and phase structure.

\section{Wstęp}

Żaroodporne i żarowytrzymałe stopy niklu stanowią priorytetową grupę materiałów stosowanych w przemyśle chemicznym, energetyce oraz lotnictwie. Wykorzystuje się je przede wszystkim do budowy elementów maszyn i urządzeń pracujących w wysokiej temperaturze

Prof. dr hab. inż. Stanisław J. Skrzypek, dr inż. Marcin Goły, Tomasz Korzeń - AGH Akademia Górniczo-Hutnicza, Kraków; dr inż. Irena Dul - WSK PZL-Rzeszów; dr hab. inż. Tomasz Babul - Instytut Mechaniki Precyzyjnej w Warszawie; Mieczysław Choroszyński - Scientific Metal Treating CO, USA przy jednoczesnym zmiennym, a także dynamicznym obciążeniu oraz działającym na nie agresywnym środowisku korozyjnym zawierającym związki siarki, azotu tlenu i węgla [1, 3].

Ze względu na skład chemiczny żaroodporne i żarowytrzymałe stopy (nadstopy) dzieli się na trzy grupy [2]: na bazie niklu, kobaltu i żelaza (zawsze z dodatkami Ni i Cr).

Ze względu na sposób umocnienia nadstopy na bazie niklu dzielimy na umacniane roztworowo, wydzieleniowo, dyspersyjnymi cząstkami tlenków [5].

Wszystkie te stopy zaliczane są do grupy materiałów metalicznych, których osnową jest austenit - faza $\gamma$ o sieci krystalicznej A1 (regularnej ściennie 
centrowanej RSC). Stabilność termiczna fazy $\gamma$, możliwość umacniania roztworowego i wydzieleniowego oraz wysoki moduł sprężystości wpływają na wysokie właściwości stopów na bazie niklu, kobaltu oraz żelaza. Rodzaj oraz zawartość głównego składnika stopowego decydują o właściwościach stopu, stabilności struktury, właściwościach w czasie eksploatacji w wysokiej temperaturze, a także odporności na korozję [1].

Stopy niklu stosowane w lotnictwie i energetyce, poza bardzo dobrymi właściwościami mechanicznymi, w tym wysokim modułem sprężystości, dodatkowo charakteryzują się niskim współczynnikiem rozszerzalności cieplnej, a także stosunkowo małym ciężarem właściwym [6]. Do typowych zastosowań nadstopów na bazie niklu należą elementy gazowych turbin przemysłowych, silników lotniczych, takich jak łopatki czy wirniki turbiny wysokiego, średniego i niskiego ciśnienia spalania [1, 4].

Nadstopy charakteryzują się wysokimi, a także stabilnymi właściwościami mechanicznymi utrzymanymi w temperaturze podwyższonej, tj. żarowytrzymałością oraz wyjątkową odpornością powierzchni stopów na działanie agresywnego środowiska w wysokiej temperaturze pracy, tj. żaroodpornością [1, 2]. W zależności od zastosowania zakres temperatury pracy nadstopów może być bardzo zróżnicowany i sięga nawet $900^{\circ} \mathrm{C}$.

Spośród wielu metod lutowania twardego w nowoczesnych gałęziach przemysłu wykorzystuje się najczęściej: lutowanie płomieniowe, indukcyjne i piecowe w atmosferach kontrolowanych, a także lutospawanie łukowe i laserowe [7]. Lutowanie piecowe w atmosferach kontrolowanych i próżni to unikalny sposób łączenia w produkcji masowej podzespołów o złożonej konstrukcji, a w przypadku produkcji jednostkowej głównie podzespołów wykonywanych z nowoczesnych inżynierskich materiałów konstrukcyjnych, należących do trudno spajalnych. Do takich materiałów należą: wysokostopowe stale odporne na korozję, metale wysokotopliwe (molibden, wolfram, niob) oraz ich stopy, metale reaktywne ( $\mathrm{Ti}, \mathrm{Zr}, \mathrm{Be}) \mathrm{i}$ ich stopy, specjalistyczne stopy żelaza i aluminium wzmacniane wydzieleniami dyspersyjnymi (ODS), nadstopy - drobnokrystaliczne i monokrystaliczne, stopy na osnowie faz międzymetalicznych (Ni-Al, Ti-Al), a także materiały kompozytowe na osnowie metalowej. Główne dziedziny zastosowania lutowania piecowego to przede wszystkim produkcja osprzętu pojazdów lotniczych i kosmicznych, produkcja turbin do energetyki, aparatury elektropróżniowej, chemicznej, pomiarowej, a także produkcja wymienników ciepła z aluminium, miedzi, tytanu i jego stopów, stali odpornych na korozję oraz stopów żarowytrzymałych [7].

Mechanizm tworzenia połączeń w procesie lutowania, w którym elementy łączone pozostają w stanie stałym, a spoiwo ulega stopieniu, uzależniony jest od wielu zjawisk fizykochemicznych, takich jak: redukcja chemiczna lub dysocjacja termiczna tlenków (na powierzchni materiałów łączonych i spoiwa), topienie (spoiwa), zjawiska związane z lutownością (rozpływność, zwilżanie, wnikanie kapilarne ciekłego spoiwa), dyfuzja i rozpuszczanie oraz krystalizacja (lutowiny) [8]. Zjawisko kapilarności w procesie lutowania twardego związane jest ze zjawiskami dyfuzji i rozpuszczania się składników lutu i powierzchni elementów łączonych, wielokrotnie określanych jako roztwarzanie lub migracja składników. Za pomocą ogólnie znanych mikroskopowych teorii dyfuzji możliwe jest opisanie mechanizmu występujących zjawisk dyfuzyjnych w zależności od właściwości fizykochemicznych spoiwa i materiałów łączonych oraz warunków metalurgiczno-technologicznych procesu lutowania.

Technologia lutowania to nie tylko samo spajanie, lecz także wiele procesów technologicznych ściśle ze sobą powiązanych, wzajemnie oddziałujących i przeprowadzanych w odpowiedniej kolejności. Takimi procesami są m.in.:

- dobór geometrii złącza,

- mechaniczne przygotowanie powierzchni,

- odtłuszczenie i mycie powierzchni,

- naniesienie powłok technicznych (np. niklowanie galwaniczne),

- zabieg nakładania lutu pod różnymi postaciami (pasty, proszki, taśmy, folie, druty),

- proces montażu i pozycjonowania całego układu przed rozpoczęciem lutowania.

Najistotniejszą operacją jest sam proces lutowania oraz dobrane parametry:

- prędkość grzania,

- temperatura i czas lutowania,

- temperatura i czas ewentualnych przystanków, tzw. przystanków temperaturowych,

- wysokość próżni,

- prędkość chłodzenia,

- wysokość tzw. ciśnienia cząsteczkowego gazu obojętnego, stosowanego w procesie lutowania, a także czas, w którym jest wtłaczany do komory pieca.

Wszystkie te operacje wpływają na wypełnienie szczeliny lutowniczej, zwilżalność powierzchni lutowanych, a tym samym na jakość wytworzonego złącza [9, 10].

W artykule opisano niektóre zjawiska przemian fazowych i zmian mikrostruktury zachodzące w obszarze stal austenityczna (X10CrNiMn20-10-2)-lut NiCrSiBFe -Inconel 625 podczas lutowania twardego w piecu próżniowym.

\section{Przygotowanie materiału do lutowania próżniowego}

Próbki w kształcie płaskowników o grubości $1 \mathrm{~mm}$. Zostały ze sobą połączone w pakiety (rys. 1) z umieszczonym pomiędzy spajanymi elementami lutowiem w postaci pasty i folii oraz poddane procesowi lutowania. Czas lutowania wynosił 5 min w temperaturze $1065^{\circ} \mathrm{C}$. 
Lutowanie wykonano w piecu próżniowym przy ciśnieniu ok. $11,3 \cdot 10^{-2} \mathrm{~Pa}$. Między powierzchniami łączonymi szczelina wynosiła $0,1 \mathrm{~mm}$. Powierzchnie łączone oczyszczono mechanicznie papierami ściernymi o gradacji 240,a następnie przemyto wodnymi środkami myjącymi.

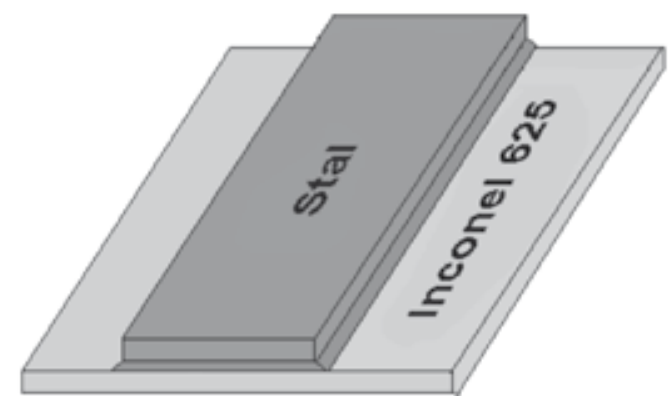

Rys. 1. Schemat połączenia lutowanego: stal austenityczna - Inconel 625 Fig. 1. Model of braized samples: austenitic steel - Inconel 625

\section{Badania metalograficzne}

Badania mikrostrukturalne połączeń lutowanych wykonano za pomocą mikroskopu świetlnego Leica $3500 \mathrm{~N}$, na prostopadłym do powierzchni próbki zgładzie metalograficznym, po trawieniu chemicznym (rys. 2). Do ujawnienia mikrostruktury spoiny lutowniczej użyto odczynnika chemicznego o składzie [6]:

- chlorek miedzi $\mathrm{CuCl}_{2}$,

- kwas solny $\mathrm{HCl}$,

- alkohol etylowy $\mathrm{C}_{2} \mathrm{H}_{5} \mathrm{OH}$.

Mikrostruktura połączenia lutowanego została przedstawiona na rysunkach 2 i 3 . Na rysunku 2 zaznaczono miejsca wykonania mikrofotografii. Lutowina jest równomierna na całej długości połączenia lutowanego (rys. 3a). Na rysunku $2 \mathrm{~b}$ widoczny jest fragment połączenia lutowanego od strony podawania pasty lutowniczej. Można zauważyć bardzo dobre wypełnienie szczeliny lutowania w całym obszarze połączenia, co świadczy o dobrej zwilżalności materiału przez ciekły lut.

Analizując mikrostrukturę lutowiny pokazaną na rysunkach 2 i 3, można stwierdzić, że dominującym składnikiem strukturalnym jest austenit $(\gamma)$ oraz umiejscowione w centralnej części lutowiny fazy międzymetaliczne z układu Ni-Cr-Si-B (rys. 2a i 2b).

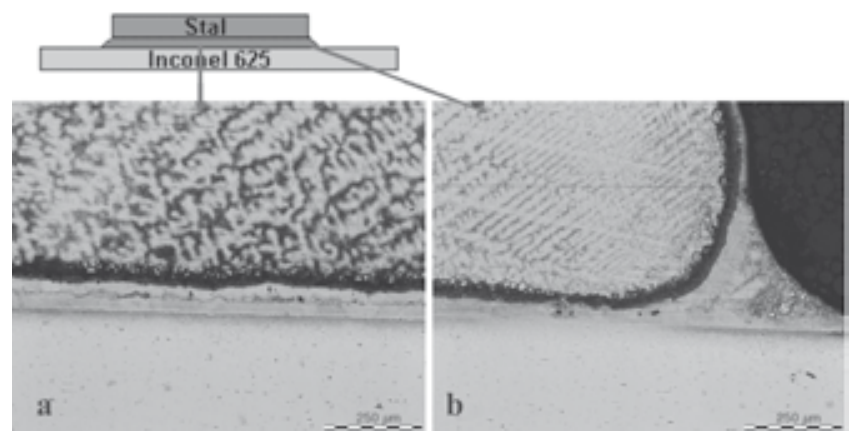

Rys. 2 Mikrostruktury połączenia lutowanego. Połączenie stali austenitycznej ze stopem Inconel 625 lutowiem NiCrSiBFe w postaci pasty: a) obszar spoiny lutowniczej; b) lico spoiny

Fig. 2. Microstructure of braized joint. austenitic steel and Inconel 625 joint with NiCrSiBFe feeler in a paste form: a) joint area; b) face of joint

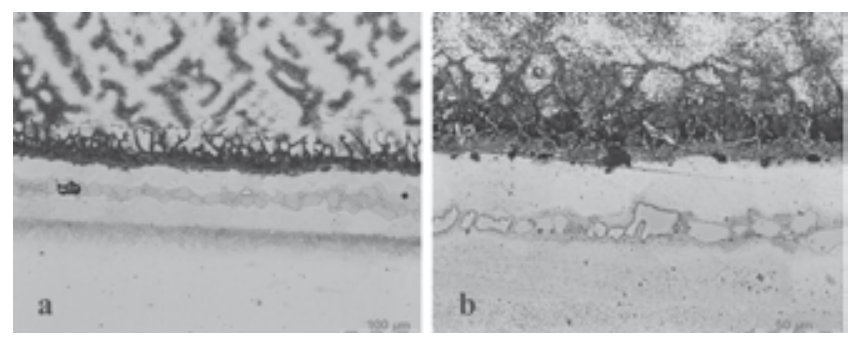

Rys. 3. Mikrostruktury połączenia lutowanego. Połączenie stali ze stopem Inconel 625 lutowiem Ni-Cr-Si-B: a) fragment połaczenia lutowanego, pow. 200x; b) obszar spoiny lutowniczej, pow. 500x

Fig. 3. Microstructure of braised joint of steel and Inconel 625 with Ni-Cr-Si-B filler: a) joint area, magn. 200x; b) joint area, magn. 500x

\section{Rentgenowskie badania dyfrakcyjne}

Pomiary rentgenowskie wykonano z tych samych obszarów, w których prowadzono badania metalograficzne na powierzchni zewnętrznej spoiny bez wstępnej preparatyki powierzchni pomiarowej.

Dyfraktogramy otrzymano przy użyciu promieniowania lampy Co na dyfraktometrze D8-Advance (rys. 4 i 5).

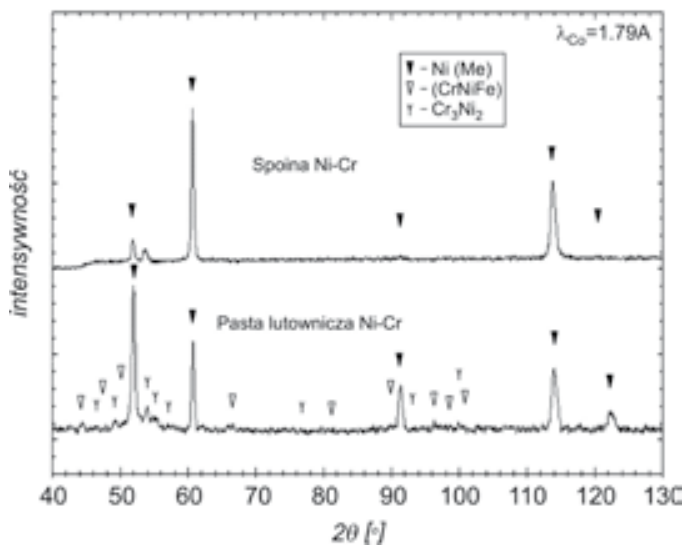

Rys. 4. Obrazy dyfrakcyjne i analiza fazowa lutu wyjściowego $\mathrm{Ni}-\mathrm{Cr}$ w postaci pasty i w lutowinie

Fig. 4. Diffraction patterns and phase analysis of solder $\mathrm{Ni}-\mathrm{Cr}$ paste and brazing area

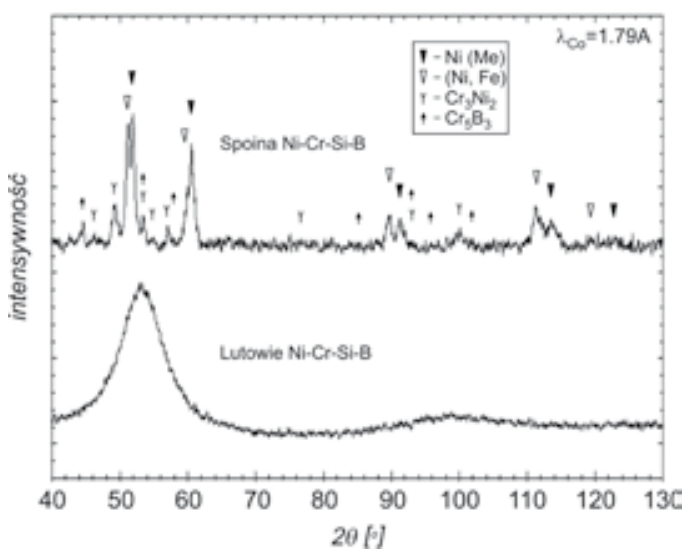

Rys. 5. Obrazy dyfrakcyjne i analiza fazowa lutu wyjściowego $\mathrm{NiCrSiBFe}$ w postaci folii w stanie amorficznym i w lutowinie w stanie krystalicznym

Fig. 5. Diffraction patterns and phase analysis of NiCrSiBFe solder foil and brazing area 


\section{Wnioski}

Wykonano eksperymentalne lutowanie dwóch stopów, tj. austenitycznej stali żarowytrzymałej z nadstopem niklu (Inconel 625).

Spoiny badano pod względem mikrostruktury i składu fazowego w stanie wyjściowym i po procesie lutowania. Zastosowane procedury technologiczne wykazały prawidłową rozpływność lutu. Jednak mikrostruktura lutu na przekroju poprzecznym wykazała niejednorodność zarówno pod względem wielkości ziarna, jak i pasmowości. Mikrostruktura ma charakter wieloskładnikowy/wielofazowy z widocznymi strefami: centralna/środkowa z eutektyką, dwie strefy boczne z dużymi i równoosiowymi ziarnami i obustronne strefy przejściowe. Na zgładzie metalograficznym po trawieniu zaobserwowano dyfuzyjną strefę przejściową/pośrednią. Wstępne pomiary wykazały, że zmiany struktury,a ich zasięg $z$ dyfuzji pierwiastków znajdujących się w lutowiu wynosił w stali austenitycznej ok. $75 \mu \mathrm{m}$, a w Inconelu 625 ok. $50 \mu \mathrm{m}$. Jednak dokładny zasięg i stopień dyfuzyjnego przemieszczenia się atomów można będzie określić po wykonaniu dodatkowych pomiarów.

Rentgenowskie badania dyfrakcyjne wykazały wystąpienie znacznych różnic między składem fazowym lutowia wyjściowego i po procesie lutowania. Największa różnica wystąpiła przy zastosowaniu folii lutowniczej w stanie amorficznym. Po procesie próżniowego lutowania lut przemienił się $w$ wielofazowy stop (dwa roztwory stałe $\gamma$ oraz dwa związki międzymetaliczne $\left.\mathrm{Cr}_{3} \mathrm{Ni}_{2} \mathrm{i} \mathrm{Cr}_{5} \mathrm{~B}_{3}\right)$.

$\mathrm{W}$ drugim przypadku lut wielofazowy (stopowy austenit niklowy, fazy międzymetaliczne CrNiFe i $\mathrm{Cr}_{3} \mathrm{Ni}_{2}$ ) zamienił się $\mathrm{w}$ stopowy austenit niklowy o innej teksturze krystalograficznej $\mathrm{z}$ niewielką ilością $\mathrm{Cr}_{3} \mathrm{Ni}_{2}$.

\section{Literatura}

[1] Mikułowski B.: Stopy żaroodporne i żarowytrzymałe - nadstopy, Wydawnictwa AGH, Kraków 1997.

[2] Hernas M., Maciejny A.: Żarowytrzymałe stopy metali, Wydawnictwo Ossolineum, Wrocław 1989.

[3] Dobrzański L.A.: Podstawy nauki o materiałach i metaloznawstwo, Wydawnictwa Naukowo-Techniczne, Gliwice 2002.

[4] Campbell F.C.: Manufacturing technology for aerospace structural materials, Elsevier B.V., Amsterdam 2006.

[5] Davies J.R. (red.): Heat-Resistant materials (ASM Speciality Handbook), ASM International 1997.

[6] Głowacki Z.: Zbiór odczynników metalograficznych, PWN Warszawa 1952.
[7] Winiowski A.: Lutowanie twarde metali - rozwój materiałów dodatkowych, technologii oraz normalizacji. Przegląd Spawalnictwa 9/2007.

[8] Winiowski A.: Lutowność w lutowaniu twardym - definicje i przykłady jej badania. Przegląd Spawalnictwa 9/2010.

[9] Dul I., Kopeć J., Poradka A., Turowska L., Babul T., Kowalski S., Jakubowski J., Senkara J.: Wpływ wybranych czynników technologicznych na proces lutowania próżniowego stopów $\mathrm{Ni}$ i stali wysokostopowej 10-8. Przegląd Spawalnictwa 10/2009.

[10] T. Babul, S. Kowalski, J. Senkara, J. Jakubowski, J. Kopeć, L. Turowska: Vacuum brazing of honeycomb seals in vane ring made of nickiel alloy: Hastelloy and Inconel by use filler material type NiCrSiB, 2 Międzynarodowa Konferencja NaukowoTechniczna pod hasłem „Postęp w technologiach lutowania”, Wrocław, 24 września, 2007.

\section{ARTYKUKY ARCHIWALNE PRZEGLĄDU SPAWALNICTWA}

\section{Cena}

Cena 1 artykułu z numeru archiwalnego w wersji elektronicznej: 21 zł (w tym 5\% VAT)

\section{W celu zamówienia artykułu należy wypełnić formularz zamieszczony obok i przesłać go w formie skanu wraz $z$ potwierdzeniem wpłaty adres:

$$
\text { pspaw@ps.pl }
$$

Wpłaty należy dokonać na rachunek bankowy: Bank BPH S.A. Oddział w Warszawie 45106000760000320000431836

\section{Artykuły wysyłane są drogą elektroniczną} w ciągu 2 dni od otrzymania zamówienia.

REDAKCJA - Przegląd Spawalnictwa AW SIMP

ul. Świętokrzyska 14a, 00-050 Warszawa tel.: 2282725 42, faks: 223361479

\section{Zamawiam artykuły:}

Nr zeszytu: ............, rok ............., strony

Nr zeszytu: ............, rok .............., strony

Nr zeszytu: ............, rok .............., strony

Adres e-mail

Imię i nazwisko

Firma

Adres

NIP

Kontakt do osoby zamawiającej:

Oświadczam, że jestem podatnikiem VAT i upoważniam firmę do wystawienia faktury bez podpisu 